\title{
Debates sobre historia intelectual: un diálogo con Elías Palti
}

\section{Debates about intellectual history: a dialogue with Elías Palti}

\section{Sheila Lopes Leal Gonçalves}

Doutoranda

Universidade Federal de Ouro Preto

leal.sheila@hotmail.com

Rua do Seminário, s/n. - Centro

35420-000 - Mariana - MG

Brasil

Palabras clave

Historia de la historiografía; Historia intelectual; Historiografía hispanoamericana.

Keywords

History of historiography; Intellectual history; Spanish-American historiography. 
José Elías Palti es uno de los intelectuales más productivos en el campo de la historia intelectual en América Latina. Ha contribuido no solo a la renovación del debate sobre el desarrollo político de Hispanoamérica, sino también con la lectura de algunos conceptos. Obtuvo su maestría (1994) y su doctorado (1997) en Historia en la Universidad de California, Berkeley. Actualmente, es investigador independiente del Consejo Nacional de Investigaciones Científicas y Técnicas CONICET, profesor de la Universidad Nacional de Quilmes (desde 1999) y de la Universidad de Buenos Aires. Algunas de sus publicaciones más relevantes son: Giro lingüístico e historia intelectual (1998), La nación como problema. Los historiadores y la 'cuestión nacional (2003) y El momento romántico: nación, historia y lenguajes políticos en la Argentina del siglo XIX (2009). Durante su participación en el $8^{\circ}$ Seminário Brasileiro de História da Historiografia (SNHH), promovido por el Núcleo de Estudos em História da Historiografia e Modernidade (NEHM) y por el Departamento de História de la Universidad Federal de Ouro Preto (UFOP), Palti concedió la siguiente entrevista.

1. Sheila Lopes Leal Gonçalves: Sobre el comienzo de su carrera de investigador, ¿cómo ha llegado al campo de la historia intelectual?

Elías Palti: Siempre en la definición de la carrera de uno hay algo de azaroso. Originalmente empecé la facultad movido por preocupaciones políticas; pensaba en estudiar algo en el campo de las humanísticas, pero oscilaba entre la filosofía 286 y la historia. Me decidí, finalmente, por la historia porque me interesaba estudiar las ideas y el pensamiento, las teorías políticas, pero quería darles como una cierta encarnadura empírica y no hacerlo de manera abstracta, como me parecía que ocurría con la filosofía. Mi orientación era más hacia el campo de la epistemología de las ciencias sociales y por eso siempre busqué combinar estos principios: la historia empírica con la teoría y el pensamiento. Inicialmente busqué vincularme con la cátedra de Historiografía, pero, finalmente, por una cuestión un tanto azarosa, me uní a la de Pensamiento Argentino y Latinoamericano (un compañero estudiante me invitó a una reunión cuando Oscar Terán estaba armando esa cátedra) y ahí fue que descubrí que la historia intelectual era, de alguna forma, esa conjunción que estaba buscando. Fue a partir de allí que empecé a profundizar en las distintas teorías y aproximaciones que hay en este campo de la historia intelectual. En ello hubo algo de azaroso, como dije, pero también algo no tan azaroso, porque fue azaroso el modo en que descubrí este campo, pero no fue casualidad que, una vez que lo descubrí, haya encontrado en él algo que respondía a mis expectativas y búsquedas intelectuales. En definitiva, la historia yo nunca la entendí como una empresa estrictamente profesional, académica. Para mí siempre fue una empresa fundamentalmente humanística, había en mí ya entonces un cierto afán de entender y conocer más allá de lo que serían las formas reductivas del historiador más profesional que simplemente trata de contar los hechos. La historia es reconstruir formas de pensamiento, culturas, épocas, formas de relacionarse socialmente los seres humanos y eso no puede estar desprendido de la dimensión intelectual. Ese es uno de los 
problemas que aún sigo teniendo con cierto medio historiográfico más tradicional, que resulta reacio a los cuestionamientos teóricos, a las preguntas acerca de por qué hacemos lo que hacemos. Normalmente el historiador no se interroga acerca de su propia profesión, salvo en lo que tiene que ver estrictamente con lo que es el arte mismo de la escritura de la historia, pero no son preocupaciones que lleven a plantearse problemáticas epistemológicas más fundamentales. En ese sentido, siempre me sentí en el medio de situaciones heterogéneas, como la historia intelectual misma, que es, de hecho, una disciplina fronteriza entre diversos campos disciplinares. Para los historiadores suelo ser muy filósofo y a los filósofos les resulto muy historiador. La historia intelectual es, como decía, resultado de ese mismo cruce y creo que es en ese cruce donde surge algo interesante, es decir, cuando uno logra ver algo que se viene estudiando desde hace mucho pero empieza a mirarlo desde otro lado distinto de cómo se ha visto hasta ahora. Cuando uno logra un cruce es que surge algo novedoso, original; de lo contrario, seguimos reproduciendo los saberes consolidados en esa propia disciplina. Para poder desestabilizar esos saberes establecidos tiene que poder enfocarse nuestro objeto desde algún lado distinto a aquel desde donde se lo viene viendo hasta aquí.

2. S.L.L.G.: Su tesis de grado es sobre Juan Bautista Alberdi. ¿La elección de ese tema se hizo bajo la influencia de Oscar Terán? ¿Qué buscaba en aquel momento con una obra sobre el pensamiento de Alberdi?

E. P.: Sinceramente ahora no te podría decir por qué elegí a Alberdi en ese momento, más allá del hecho de que era uno de los autores preferidos de Oscar Terán y al que él estaba estudiando en ese momento también. No me acuerdo ahora qué es lo que me interesó en Alberdi entonces. Pero repasando lo que escribí, hace muchos años, me llama la atención encontrar ya, tan tempranamente, esbozadas algunas de las problemáticas que hoy mismo me interesa investigar. Cuando escribí esa tesis sobre Alberdi yo era estudiante y todavía no conocía a ninguno de esos autores con los que hoy trabajo, ni a Skinner, ni a Koselleck, ni a Rosanvallon, etc. Sin embargo, la tesis me llevó a un cuestionamiento serio de los modos como se escribía la historia intelectual y más específicamente sobre el modo en que había sido abordado el pensamiento de Alberdi. El título, Alberdi y su pensamiento, tiene, en realidad, algo de irónico, porque una de las hipótesis que presidía el texto era, justamente, la de que no existía tal cosa como un "pensamiento" de Alberdi, porque Alberdi cambió mucho a lo largo de toda su vida y, entonces, no se puede hablar de "un" pensamiento de Alberdi. Si no se lo contextualiza, uno bien puede tomar el Alberdi de Crimen de la guerra y hablar del suyo como un pensamiento pacifista. Pero para ello debe dejarse de lado el hecho de que él negoció la intervención militar de Francia en Argentina, porque estaba enfrentando a [Bartolomé] Mitre. Entonces, ¿cuál es el pensamiento de Alberdi? En un momento Alberdi condenó la guerra en Paraguay, en una denuncia sumamente poderosa contra la guerra, pero en otro momento argumentaba a favor de la intervención militar de las potencias europeas. En definitiva, uno no 
puede decir cuáles son las ideas de Alberdi si no las contextualiza y ello es así con cualquier autor que quiera tomarse. Hablar del pensamiento de Alberdi o de Sarmiento o de quien sea supone siempre un recorte arbitrario de sus ideas, tomar de todo lo que dijo ese autor simplemente lo que a uno le gusta y dejar lo que no le gusta. Eso me parecía totalmente arbitrario, por eso empecé a buscar otras formas de entender la historia intelectual que no pasaran por reconstruir sistemas de pensamiento, que no existen en la realidad. Tampoco se trataba de apelar al recurso trillado de las "contradicciones" del autor en cuestión, que no es más que la contracara de la búsqueda de coherencia del pensamiento. Lo que yo busqué, en cambio, es como dar un sentido más propiamente histórico a esos escritos, relacionándolos con el contexto más preciso de emergencia del cual surgieron esos tipos de problemas a los que en cada momento se estaba enfrentando dicho autor, entender qué preguntas se estaba en cada caso planteando e intentaba responder.

3. S.L.L.G.: A partir de eso, ¿se podría decir que el trabajo que desarrolla hoy comenzó allí, debido a la insatisfacción con la clase de historia intelectual que se estaba haciendo hasta entonces?

E. P.: Sí, es así. Lo que leí entonces acerca de la historia intelectual latinoamericana me resultaba muy poco estimulante. Toda la historia intelectual argentina, y diría latinoamericana, en el siglo XIX estaba orientada en un mismo

288 sentido. Sobre Alberdi, en particular, había una enorme bibliografía y toda estaba ordenada en torno a una misma preocupación: tratar de determinar cuán historicista o cuán iluminista era Alberdi. Unos van a decir que era más historicista que iluminista, otros lo contrario y otros, finalmente, que era un ecléctico, pero ya está, mucho más no se podría decir al respecto, no hay muchas más opciones que esas. Sinceramente, si yo tenía que escribir una tesis para determinar cuán historicista o iluminista era Alberdi, prefería no escribir nada; no tendría sentido seguir repitiendo eso. A partir de ahí inicié una búsqueda para ver qué otro tipo de preguntas uno les puede plantear a esos textos y que no se limiten a intentar rastrear la filiación de pensamiento de sus ideas, procedimiento que, en algunos casos, llega a límites paródicos. Por ejemplo, uno de los fundadores de la historia de las ideas argentina, que fue decano en la Facultad de Filosofía y Letras, Coroliano Alberini [La metafísica de Alberdi, 1934] llega a plantear eso en términos de porcentajes: tal autor es $80 \%$ iluminista y $20 \%$ historicista, etc. Eso, a su vez, para esos autores tendría connotaciones políticas, porque suponen que ser historicista significa ser más nacionalista y ser iluminista significa ser más democrático y cosmopolita. Otros van a alterar las valoraciones, pero todas ellas son construcciones arbitrarias que no ayudan a entender nada respecto de qué estaba concretamente escribiendo Alberdi y por qué escribió lo que escribió. Determinar cuán historicista o iluminista era no ayuda a entender las preocupaciones y la trayectoria concreta de Alberdi, cómo surge concretamente cada texto, a qué tipo de problemática se estaba confrontando en cada momento histórico. 
4. S.L.L.G.: ¿Esa preocupación por determinar la presunta afiliación de las ideas de los autores estudiados tiene que ver con la situación política en la Argentina que había producido esa historiografía?

E. P.: En realidad, eso que aparece recién en el siglo XIX retoma, en gran medida, aquello que decían los propios autores a los que se analiza. En el caso de la llamada Joven Generación (que es a la que pertenecía Alberdi), la oposición entre romanticismo e iluminismo se va a vincular con la polémica que pretenden entablar con la generación precedente. Ellos, para legitimarse a sí mismos, tienen que decir contra qué supuestamente vienen a reaccionar, $y$, según dicen, vienen a reaccionar contra una tradición iluminista que supuestamente solo se movía en función de principios abstractos, desconociendo la realidad concreta a la que esos principios debían aplicarse. Siguiendo con ese mismo esquema, los historiadores van a interpretar toda la historia intelectual argentina como tensionada entre aquellos pensadores iluministas (más europeístas, abstractos) y aquellos pensadores historicistas que tenían una vocación por precisar las condiciones locales de asimilación de esos modelos extranjeros. Para ellos, toda la historia intelectual giraría así en torno de esos dos polos: unos más orientados a las ideas puras y a los modelos europeos y otros más preocupados por las peculiaridades locales, por las adecuaciones de los modelos a las necesidades particulares de un medio social. iLo que es terriblemente aburrido, además de bastante absurdo!, ¿no? En todo caso, obviamente, no se puede creer lo que los mismos autores dicen, dado que eso que dicen es, en realidad, parte de una contienda ideológica de la que ellos participan; no se trata de una mera constatación de una realidad, sino de una cierta operación ideológica que ellos realizan. Lo que habría que hacer es tratar de entender qué los llevo a decir lo que dijeron, partiendo de la base de que lo que dicen no es porque sea efectivamente así, sino que detrás de esos dichos se esconde un cierto proyecto político. Por ejemplo, cuando se hace el Salón Literario de 1837, va a haber tres discursos: el de Alberdi, el de Marcos Sastre y el de Juan María Gutiérrez. Marcos Sastre era más prorrosista, fue el que más insistía en romper con las ideas europeas de los ilustrados. Juan María Gutiérrez, en cambio, estaba ya más vinculado a los unitarios exiliados. Gutiérrez se escribe con Florencio Varela, un unitario, quien le responde que no entiende el interés del señor Marcos Sastre en poner tanto énfasis en ideas con las que nadie puede estar en desacuerdo. Es absurdo pensar que los unitarios desconocían el hecho de que todas las constituciones no eran igualmente buenas en cualquier momento $o$ en cualquier lugar, que había que adecuarlas a cada realidad particular. Tomar literalmente esas acusaciones sería absurdo. De hecho, algunos llegan al límite de lo paródico. En México, por ejemplo, se decía de Miguel Macedo que se vestía según el pronóstico meteorológico de Londres. Sarmiento, en Facundo [1845], dice que él podría reconocer un unitario entre cien porque el unitario camina siempre con la frente alta y nunca da el brazo a torcer. Si los hechos muestran lo contrario, él simplemente los ignora, cree, dice que puede refutar la realidad con argumentos. Todo eso es un absurdo si lo tomamos literalmente $y$, sin embargo, 
toda la historia de las ideas en Argentina repite eso: que los románticos vinieron a dar un sentido de realidad que estaba ausente en los ilustrados, que solo estaban movidos por principios abstractos, etc. etc. O sea, reproducen lo que esos mismos autores decían, como si fuera la verdad, sin nunca cuestionar o entender qué estaba en juego detrás de esas afirmaciones. Todo eso empezó a generar en mí la necesidad de buscar nuevos marcos teóricos. El punto fundamental era que no bastaba con cuestionarse la literatura existente para romper efectivamente con ese marco conceptual que era propio de la historia de las ideas; todavía faltaba lo más importante. Yo ya sabía qué era lo que no quería; ahora, ¿cómo desarrollar marcos teóricos que me permitieran, a su vez, elaborar nuevas preguntas?

5. S.L.L.G.: En cuanto a esos marcos teóricos, ¿está hablando de Skinner, Pocock, Koselleck, Dominick LaCapra? Y ¿cómo llegó a ellos? ¿En qué momento de su formación académica se dio eso?

E. P.: Algo empecé a leer en Argentina. Pero muy poco después que terminé esa tesis [Alberdi y su pensamiento], viajé a Estados Unidos, estuve seis años en Berkeley, hice mi doctorado y ahí fue que empecé a conocer a la mayoría de esos autores. Y allí también tuve la suerte de estudiar con Martin Jay, que es uno de los más importantes historiadores intelectuales de los Estados Unidos. Cursé varios seminarios, él formó parte de mi comité de tesis y gracias a él

290 conocí a muchos de esos autores. Después, se va armando una cadena, conoces a uno y ellos te van remitiendo a otros. Poco a poco pude construir el mapa de las nuevas corrientes de la historia intelectual.

6. S.L.L.G.: Así que su tiempo en Berkeley significó un hito importante en sus propias aportaciones teóricas...

E. P.: Sí. En realidad, después se fue ampliando un poco más el espectro porque, poco a poco, descubrí hasta qué punto también era importante, para entender el pensamiento político y el pensamiento histórico y, sobre todo, para el siglo XIX, la historia de la ciencia. La historia de la ciencia marcó mucho, entonces, todo el pensamiento; y fue ahí que empecé a estudiar bastante sobre historia de las ciencias naturales, de la biología en particular. Fue muy sorprendente para mí empezar a darme cuenta de que hay ciertas estructuras de pensamiento que subyacen a las ideas de cada autor particular y de que por lo tanto es imposible entender concretamente qué dice este si uno no lo inserta dentro de esos entramados discursivos dentro de los cuales esas ideas están funcionando. Tomadas en sí mismas, claro, se vuelven ideas muy abstractas y genéricas, que se pueden encontrar en cualquier lugar. De hecho, el iluminismo e historicismo, para la historia de las ideas, no constituyen horizontes conceptuales históricamente localizados y localizables, sino que se trataría de una oposición eterna o cuasi eterna que atraviesa toda la historia intelectual moderna y llega incluso hasta el presente. Es decir, todos los pensadores de la historia de la humanidad podrían ser 
clasificados en términos de cuán iluministas o historicistas eran, desde Sócrates hasta Deleuze. Según ese esquema, bien se podría decir que Sócrates era más iluminista y Aristóteles más historicista y así sucesivamente. Y eso es así porque el propio esquema teórico delimita las opciones posibles ya de antemano, no hay muchas opciones posibles, entonces todos tienen que entrar dentro de esa grilla dicotómica. Poco a poco voy descubriendo qué es lo que estaba mal en ese tipo de procedimiento. Si miramos todo desde el punto de vista de las ideas, el procedimiento parece perfectamente razonable, no habría nada malo o absurdo en pensar que Sócrates era iluminista. El problema justamente radica en que lo que historiza y particulariza cada forma de pensamiento no se encuentra en el contenido de las ideas, sino en las estructuras, las formas, la lógica según las cuales se van a articular esas ideas entre sí. Si nos quedamos solamente en el plano de la superficie de las ideas, sin penetrar la lógica que en cada caso las articula entre sí, estas aparecen siempre como entidades transhistóricas que pueden descubrirse en los contextos intelectuales más disímiles. Muchas veces las ideas sí son las mismas; son los modos en que están articuladas en cada discurso los que son distintos, los que cambian históricamente. De lo que se trata es de reconstruir esa lógica de articulación de las ideas más que las ideas en sí mismas. Es a partir de ahí que uno puede encontrar qué es lo que especifica cada forma particular de discurso.

7. S.L.L.G.: Volviendo a Oscar Terán y a otros historiadores de aquel tiempo, ¿cuál es el impacto de la historiografía de su época en los trabajos de hoy?

E. P.: Cuando conocí a Terán, se había vuelto un historiador intelectual reconocido por sus trabajos sobre el positivismo. El positivismo, en los años en que empecé a trabajar en este campo, se había convertido en uno de los núcleos problemáticos de la historia intelectual latinoamericana, sobre todo a partir del caso mexicano. Luego de la Revolución Mexicana se va a ver, también retrospectivamente, a los positivistas como el máximo ejemplo de mentalidad europeizante y racionalista. La revolución va a coincidir con una reacción antipositivista. A los positivistas los van a empezar a llamar despectivamente "Ios científicos" y se los va a identificar cada vez más con el porfiriato [gobierno de Porfirio Díaz], régimen contra el cual se levantó la Revolución Mexicana. Por detrás de la discusión en torno al positivismo va a estar subyaciendo así una discusión mayor sobre la posibilidad de encontrar un pensamiento latinoamericano propio. Había cierta idea subyacente de que las elites intelectuales desconocían la realidad local, que seguían pensando América Latina según categorías extrañas, exóticas, y de lo que se trataba era de desprenderse de esos ropajes importados para dar lugar a una expresión más auténtica de nuestro auténtico ser nacional y latinoamericano, lograr y expresar en el plano de la filosofía, del pensamiento, nuestra esencia particular como latinoamericanos. Es ahí que nace la filosofía latinoamericana. Cuando asume la cátedra como titular de Pensamiento Argentino y Latinoamericano, Oscar va a venir de alguna forma a cuestionar justamente esa tradición de la filosofía latinoamericana, que todavía en esos años era muy fuerte. Hoy ya es 
más bien marginal; la idea de que existe una filosofía latinoamericana sigue presente, pero en zonas marginales del debate historiográfico. En ese momento, en los años 1980, todavía era una batalla teórica importante y Oscar fue uno de los paladines, de alguna forma, en desestabilizar esa visión cerradamente esencialista de América Latina. Y el positivismo estaba entonces en el ojo de la tormenta. En el fondo de la discusión yacía la preocupación acerca de la existencia o no de una filosofía nacional, sobre si es posible una filosofía nacional o una filosofía latinoamericana, y Oscar Terán fue clave para desestabilizar esa perspectiva esencialista de lo nacional y lo latinoamericano.

8. S.L.L.G.: ¿Qué piensa sobre el actual escenario de los debates en el campo de la historia intelectual de América Latina, particularmente en Brasil?

E. P.: En realidad, los marcos teóricos que se trabajan en Brasil y en la América hispana no son muy distintos. Para empezar, son bastante variados. Tanto en un lado como en otro hay algunos historiadores intelectuales más orientados a la historia conceptual, en su vertiente alemana, y otros más inclinados hacia la vertiente anglosajona. En eso no difieren mucho. Se encuentran, sí, algunas bifurcaciones llamativas en el modo en que se aplican concretamente esos marcos teóricos. Un ejemplo es el debate que se da hoy en torno del bicentenario de la Independencia. Ha habido una oleada de estudios acerca de las revoluciones de independencia y eso ha dado lugar a una serie de estudios nuevos que se 292 definen a sí mismos como revisionistas, tanto en Brasil como en la América hispana. La paradoja es que en la América hispana y en Brasil el revisionismo parte de los mismos marcos teóricos y, sin embargo, la idea de revisionismo cobra sentidos opuestos. Porque en la América hispana el revisionismo, digamos, contra lo que va a reaccionar es contra las visiones épicas de que las revoluciones de independencia, según las cuales estas fueron una especie de aurora de la libertad, el triunfo final de los idearios ilustrados de libertad e igualdad, etc. El revisionismo viene a cuestionar esos relatos nacionalistas mostrando que esas naciones no existían realmente antes de la independencia, sino que fueron el resultado de esa misma independencia, por lo que afirmar que esta se produjo como resultado de reclamos de soberanía de naciones preexistentes resulta anacrónico. Pero, además, esas perspectivas revisionistas tienden a negar que la independencia haya marcado una verdadera ruptura. Más allá de los cambios políticos, afirman que los imaginarios e instituciones tradicionales coloniales permanecieron mayormente inalterados. En la América portuguesa, en Brasil, el revisionismo, en cambio, quiere decir justamente lo contrario. Partiendo de los mismos marcos teóricos, terminan extrayendo conclusiones opuestas: lo que los revisionistas brasileños hoy discuten es la visión más bien continuista de la historia brasileña, ejemplificada por Caio Prado Jr, según la cual la independencia no supuso ninguna ruptura real, en la medida en que en Brasil, como sabemos, continuó el esclavismo, la monarquía, etc. Entonces la visión más tradicional tendía allí a enfatizar la continuidad entre la colonia y el periodo independiente. Frente a ello, el revisionismo aquí, contrariamente a lo que sucede en la América hispana, 
tiende a destacar que, más allá de esas continuidades, la ruptura del orden colonial supuso una serie de transformaciones cruciales en términos políticos.

\section{S.L.L.G. : Sí, porque el proceso de la Independencia de Brasil fue muy diferente al de la América hispana...}

E. P.: La paradoja es esa, que el revisionismo, a partir de ciertas preocupaciones comunes, termina sin embargo bifurcándose. Ambos parten de la idea de que las visiones tradicionales son fuertemente teleológicas. En el caso de la América hispana, porque creen descubrir en el mismo origen del proceso de ruptura del orden colonial la presencia de una entidad, la nación, que solo existe como resultado de ese mismo proceso revolucionario. En el caso de la América portuguesa también se plantea que hay una visión tradicional teleológica, pero ese teleologismo contra el cual se reacciona es otro. En este caso es el teleologismo de aquellos que niegan el carácter revolucionario de las revoluciones de independencia, en la medida en que parten de un cierto modelo de qué es lo que debió haber sido la revolución y, como lo que ocurrió no coincide con lo que a ellos les hubiera gustado que ocurriera, niegan el hecho de que se trató de una revolución, sin preocuparse por tratar de entender qué es lo que cambió, más allá de lo que ellos querían que hubiera cambiado o que suponen que debería haber cambiado. Efectivamente, cambiaron muchas cosas. Esa visión continuista tiene una fuerte impronta normativa y teleológica. En fin, ambos revisionismos parten de los mismos marcos teóricos, ambos buscan rechazar las perspectivas teleológicas de la historia y, sin embargo, en los dos lados, y esto es sugestivo, lo hacen por vías claramente contradictorias entre sí. Me parece un fenómeno bastante notable y una vez traté de explicar esa paradoja que se da en torno del bicentenario.

10. S.L.L.G.: Eso nos hace pensar aún más en esas conexiones, en los intercambios que se han hecho, en el movimiento cada vez más grande que vemos entre los investigadores en Brasil y en la América española...

E. P.: Volviendo a lo que decía antes, es muy interesante fomentar este tipo de intercambios. En primer lugar, para poder ver esas paradojas, que los hispanoamericanos no piensen que el revisionismo es tal cosa y puedan entender que hay en otros lugares gente que entiende ese revisionismo de formas muy distintas, que no hay una única forma de entender el revisionismo, hasta qué punto tanto las visiones rupturistas como las continuistas son igualmente unilaterales y tienen bastante de arbitrario. Los nuevos marcos teóricos, la llamada nueva historia intelectual, no determina una visión rupturista o continuista. Hacer la nueva historia política no necesariamente supone, como creen los hispanoamericanos, sostener una visión continuista de la historia ni se reduce a eso. Ni tampoco supone, como creen los historiadores brasileños, enfatizar las rupturas. Los intercambios permiten, de alguna forma, contrastar perspectivas opuestas y poner más en perspectiva los propios modelos de que los cuales se parte. 
11. S.L.L.G.: Hoy es el último día del $8^{\circ}$ Seminário Brasileiro de História da Historiografia y me gustaría saber lo que piensa de las discusiones que se presentan aquí.

E. P.: Es interesante este tipo de reunión y lo más interesante es que tiene un formato más intensivo que los congresos tradicionales. Es, diría, una mezcla de congreso con workshop, lo que permite un tipo de intercambio bastante más profundo de lo que suele haber en los congresos. Te confieso que en estos últimos años me volví algo escéptico respecto al formato tradicional del congreso, me resulta algo rígido y que tiende a dar lugar a presentaciones más bien formales. Me parece que si lo que se quiere es, como en este caso, afirmar un campo disciplinar, como es el de la teoría de la historia y la historiografía, se necesitan este tipo de reuniones que posibiliten intercambios intelectuales más intensos, sobre todo teniendo en cuenta, como decía antes, que el medio historiográfico es bastante reacio a los debates teóricos. De hecho, mi materia, la que yo dicto en la Facultad de Filosofía y Letras de la UBA [Universidad de Buenos Aires], se dicta en el departamento de Filosofía, no en el de Historia, como sería de esperar. No hay ninguna materia de historia intelectual en la carrera de Historia. Entonces, me parece que tratar de multiplicar este tipo de encuentros resulta fundamental para consolidar un campo que en la profesión histórica ha sido y sigue siendo todavía bastante marginado, simplemente por considerarse ajeno a las preocupaciones concretas de los historiadores empíricos. De lo que

294 se trata, en definitiva, es de romper cierto positivismo todavía muy enraizado entre los historiadores. En esto me parece que estas iniciativas, y sobre todo la posibilidad de establecer vínculos y redes a nivel latinoamericano, permitirán dinamizar el campo y sobre todo dar mayor visibilidad a los aportes que se están haciendo en esta provincia particular de la teoría de la historia. El objetivo, entiendo, es hacer entender hasta qué punto las preguntas acerca de la teoría de la historia resultan fundamentales para desarrollar investigaciones históricas que sean realmente innovadoras. Es únicamente a partir de una incursión por la teoría que se pueden reformular los modos establecidos de aproximaciones a la historia. Inversamente, la investigación empírica puede eventualmente servir para plantear interrogantes o cuestionar los modelos teóricos de los que partimos. Pero el punto es que, si no se establece ese diálogo, resulta muy difícil evitar terminar haciendo trabajos monótonos y reiterativos. Solo en ese juego de interacción entre teoría e investigación empírica entiendo que pueden objetivarse y eventualmente ponerse en cuestión los supuestos sobre los que se asientan los saberes establecidos en un cierto campo.

12. S.L.L.G.: Hemos visto, en América Latina, el aumento de la inversión en investigación, especialmente por parte del gobierno. ¿Cómo es esa relación en Argentina, entre la universidad y los estímulos a la investigación y la enseñanza?

E. P.: En los últimos años, el último gobierno ha aumentado en general los fondos a las investigaciones. En Argentina, como en todo el mundo, se enfatizan 
más las investigaciones de las ciencias duras y menos las humanísticas. En líneas generales aumentó mucho el presupuesto para la investigación. Ahora, esto lo digo partiendo de la base de que en Argentina siempre el presupuesto para la educación superior ha sido muy inferior a lo que suele ser en otros países. De hecho, en Argentina, el CONICET estuvo cerrado casi una década. Es algo muy argentino eso, la despreocupación por la educación superior y la investigación. El contraste de cómo se comportó la dictadura brasileña en comparación con la argentina es ilustrativo al respecto. Mientras que en Brasil los militares alentaron, por ejemplo, el desarrollo de los posgrados, en Argentina no se difundieron los posgrados sino hasta hace muy poco. El fenómeno característico es que, mientras que en América Latina, normalmente, los países expulsan mano de obra poco calificada y buscan atraer mano de obra calificada, Argentina, por el contrario, siempre se caracterizó por atraer mano de obra no calificada y expulsar mano de obra cualificada. Ello es así porque siempre hubo en Argentina muy poca preocupación por atraer y retener la mano de obra altamente calificada, lo que es completamente irracional, porque el Estado argentino invierte en la formación de recursos humanos que después terminan aprovechando otros países.

\section{5}

